\title{
Gastrointestinal stromal tumor
}

INSERM

\section{Source}

INSERM. (1999). Orphanet: an online rare disease and orphan drug data base.

Gastrointestinal stromal tumor. ORPHA:44890

Gastrointestinal stromal tumor (GIST) is the most common mesenchymal neoplasm of the gastrointestinal (Gl) tract, typically presenting in adults over the age of 40 (mean age 63), and only rarely in children, in various regions of the Gl tract, most commonly the stomach or small intestine but also less commonly in the esophagus, appendix, rectum and colon. GIST s can be asymptomatic or present with various non-specific signs, depending on the location and size of tumor, such as loss of appetite, anemia, weight loss, fatigue, abdominal discomfort or fullness, nausea, vomiting, as well as an abdominal mass, blood in stool, and intestinal obstruction. GISTs can also be seen in familial syndromes such as Carney triad and neurofibromatosis type 1. 